\title{
Assessing Occurrence and Biological Consequences of Contaminants of Emerging Concern on Oceanic Islands
}

\author{
Kelly M. Diamond ${ }^{1,2} \mathbb{D}$, Christopher J. Good $^{3}$, Nina Johnny ${ }^{4}$, Troy S. Sakihara ${ }^{5} \mathbb{D}$, Paul L. Edmiston ${ }^{3}$, \\ Jennifer A. Faust ${ }^{3}\left(\mathbb{D}\right.$, Tonya C. Schoenfuss ${ }^{6}{ }^{\mathbb{D}}$, Alexander M. Rubin ${ }^{7}$, Richard W. Blob ${ }^{1}(\mathbb{D}$ \\ and Heiko L. Schoenfuss $4, * \mathbb{D}$
}

1 Department of Biological Sciences, Clemson University, Clemson, SC 29631, USA; kellymgdiamond@gmail.com (K.M.D.); rblob@clemson.edu (R.W.B.)

2 Center for Developmental Biology and Regenerative Medicine, Seattle Children's Research Institute, Seattle, WA 98101, USA

3 Department of Chemistry, The College of Wooster, Wooster, OH 44691, USA; cj.good@wooster.edu (C.J.G.); pedmiston@wooster.edu (P.L.E.); Jfaust@wooster.edu (J.A.F.)

4 Aquatic Toxicology Laboratory, St. Cloud State University, St. Cloud, MN 56301, USA; njohnny@stcloudstate.edu

5 Division of Aquatic Resources, Department of Land and Natural Resources, State of Hawaii, Hilo, HI 96720, USA; troy.s.sakihara@hawaii.gov

6 Department of Food Science, University of Minnesota, St. Paul, MN 55108, USA; tschoenf@umn.edu

7 School of Life and Environmental Sciences, University of Sydney, Sydney, NSW 2006, Australia; alexander.rubin@sydney.edu.au

* Correspondence: hschoenfuss@stcloudstate.edu

check for

updates

Citation: Diamond, K.M.; Good, C.J.; Johnny, N.; Sakihara, T.S.; Edmiston, P.L.; Faust, J.A.; Schoenfuss, T.C.; Rubin, A.M.; Blob, R.W.; Schoenfuss, H.L. Assessing Occurrence and Biological Consequences of Contaminants of Emerging Concern on Oceanic Islands. Water 2022, 14, 275. https://doi.org/10.3390/ w14030275

Received: 2 December 2021

Accepted: 16 January 2022

Published: 18 January 2022

Publisher's Note: MDPI stays neutral with regard to jurisdictional claims in published maps and institutional affiliations.

Copyright: (c) 2022 by the authors Licensee MDPI, Basel, Switzerland. This article is an open access article distributed under the terms and conditions of the Creative Commons Attribution (CC BY) license (https:// creativecommons.org/licenses/by/ $4.0 /)$.

\begin{abstract}
Freshwater streams on oceanic islands serve critical ecological and economic functions. However, these are underrepresented in assessments of pollution from contaminants of emerging concern (CEC). Furthermore, freshwater streams and their endemic fauna often have characteristics that are distinct from those of continental streams and model species, calling extrapolations from studies of such systems into question for island streams. In the current study, we assessed the presence of CEC across three sampling events and five freshwater streams on the Island of Hawai'i. We also exposed juveniles of the native fish species Sicyopterus stimpsoni to a mixture of commonly co-occurring CEC for $96 \mathrm{~h}$ in static renewal experiments, testing for impacts of CEC in two ecologically relevant assays of functional performance. CEC from multiple sources were ubiquitous in Hawaiian streams, including human-use pharmaceuticals, agricultural herbicides, and industrial runoff. Concentrations of CEC were comparable to published studies from continental streams, exceeding total concentrations of $1000 \mathrm{ng} / \mathrm{L}$ for the eight quantified CEC in four samples, and approaching $2500 \mathrm{ng} / \mathrm{L}$ in one sample. Effects on exposed fish were subtle and limited to treatments with higher CEC concentrations but indicated potential impacts of CEC on locomotor performance. These results indicate that Hawaiian streams follow a global trend of widespread freshwater pollution by CEC that are accompanied by subtle effects on native fish species and highlight the need for the inclusion of endemic species and ecologically relevant assays when assessing the effects of contaminants in island habitats.
\end{abstract}

Keywords: fish; Hawaii; freshwater; pharmaceuticals; exposure-activity ratios

\section{Introduction}

The vast marine riches that surround oceanic islands frequently overshadow the paucity of fresh waters in these settings. The dearth of fresh waters on oceanic islands is particularly severe for many tropical volcanic islands. On islands, natural limits to freshwater availability as a result of porous volcanic soils, steepness, and reliance on orographic rain, are compounded by the impacts of tourism-driven population growth [1]. Tropical rains, often brief and intense, can quickly move contaminants from the terrestrial environment into streams, or through permeable volcanic soil into groundwater. Understanding the 
consequences of contaminant exposure on freshwater organisms residing in island streams is further complicated because these ecosystems are unlike their continental counterparts with unique species assemblages and life histories (for example: diadromous migrations).

The Hawaiian Islands are the most remote chain of islands on earth, perched over a volcanic hot spot in the middle of the Pacific Ocean. Rainfall on the island is initiated by clouds cooling as they ascend the flanks of the volcanoes, resulting in an uneven distribution of precipitation ranging from over $600 \mathrm{~cm}$ of rain on the eastern (windward) Hamakua Coast, to less than $25 \mathrm{~cm}$ precipitation along the western (leeward) Waikoloa Coast (http:/ / rainfall.geography.hawaii.edu/, (accessed on 1 December 2021)). Watersheds are small, steep, and concentrated on the windward side of the island. These watersheds are used extensively for livestock and row crop agriculture and, more recently, have been affected by urban sprawl, with homes relying on onsite wastewater treatment systems ("septic systems") and old cesspools [2]. In contrast to rivers in continental settings, most wastewater treatment plants on oceanic islands discharge near the ocean or directly into the ocean, largely eliminating treated wastewater effluent a source of contaminants for stream environments. Frequent flash floods, especially during the spring rainy season, can easily transport organic matter, pathogenic bacteria [3], and anthropogenic compounds such as pharmaceuticals, pesticides, and other industrial and personal care products off the landscape, through streams and estuaries, and ultimately into the ocean [4]. Many of these compounds represent contaminants of emerging concern (CEC), a grouping of chemicals loosely defined as either being introduced to the environments in the past few decades, recently discovered in the environment, or having newly discovered toxicological properties that have not been evaluated previously. In Hawai'i, most existing data were collected in marine or estuarian environments surrounding the archipelago [4,5]. The potential impacts of these CEC on the freshwater biota of islands like Hawai'i are not well understood, as few studies have focused on these distinct environments (e.g., [6]).

Freshwater fish assemblages on oceanic islands, including those on the Hawaiian Islands, have little in common with continental streams [7]. The short hydrologic retention time of water in island streams inhibits primary production [8], and food webs are often limited to a few key species [9]. Furthermore, while the majority of continental fish species belong to the order Cypriniformes, which includes key toxicological model species such as fathead minnows (Pimephales promelas) and zebrafish (Danio rerio), fish in oceanic island streams are often derived from other lineages with distinct life history features. For example, only about $0.01 \%$ of fishes migrate regularly between marine and freshwater environments [7], but such anadromous species typically represent major components of the freshwater fauna on oceanic islands [7]. Larval or juvenile migrations from marine environments back to freshwater habitats represent windows of vulnerability, as migrating organisms undergo profound physiological changes [10] while navigating estuaries with high predator densities and, on young volcanic islands, additional obstacles including high velocity currents and steep stream inclines [11]. Exposure to CECs has been documented, to increase reaction times to predator approach, affect locomotor performance, and reduce larval survival with detrimental consequences to population sustainability [12,13]. These biotic and abiotic factors complicate the assessment of risk associated with pollution. For example, standard operating procedures such as Organisation for Economic Co-operation and Development (OECD) exposure guidelines (for example, OECD 229: OECD Guidelines for the testing of chemicals) may stipulate exposure conditions (for example: duration of exposure, temperature, photoperiod) not appropriate for species native to island habitats.

In this study, we tested the hypotheses that (1) CEC were common in Hawaiian freshwater streams, and (2) that exposure to CEC would adversely impact predator avoidance and locomotor performance of native Hawaiian stream fishes in a dose-dependent fashion. We chose these performance endpoints as they are critical to the migratory success of this species and more relevant than standard apical endpoints such as larval growth (complicated by the concurrent diadromous migration) and survival (mortality at this life stage is mostly associated with intense predatory pressure [14]. To test our hypotheses, 
we sampled five streams along the Hamakua Coast of the Island of Hawai'i, on three occasions, for CEC commonly reported in environmental samples and representing several classes of compounds (i.e., pharmaceuticals, personal care products, agrichemicals, and industrial compounds). To assess the effects of CEC on migrating juvenile stream fishes returning from the ocean, we exposed native juvenile gobiid fish (Sicyopterus stimpsoni) for $96 \mathrm{~h}$ to a mixture of CEC prior to evaluating their performance via predator-avoidance assays and sustained locomotion. As there were no data on CEC occurrence in Hawaiian streams available at the time of the exposure experiments (which were concurrent with environmental sampling), we developed a CEC mixture consisting of 14 compounds (Table 1) commonly present in many aquatic environments impacted by anthropogenic activity ([15,16]; reviewed in [17]), and because land use on the Hamakua Coast (agriculture, rural dwellings relying on septic systems) suggests their presence is likely [2]. We chose the Hawaiian freshwater goby S. stimpsoni as a representative species for this study because its natural history includes a juvenile migration from marine to fresh waters [10], during which individuals are confined to the estuary for $48-96 \mathrm{~h}$ as they undergo a profound metamorphosis of cranial structures that may be affected by CEC [18]. Additionally, S. stimpsoni is a gobiid fish and is closely related to a large group of sicydiine species that are commonly found in insular freshwater environments across tropical and subtropical regions of all oceans [19]. Together, our experiments in this system aim to evaluate the presence and potential impacts of CEC on native insular fauna and highlight the complexity of assessing pollutant risk in non-standard biological settings.

Table 1. Confirmatory water chemistry (mean \pm st. dev; ng/L) across predator performance exposure experiments in 2017 and climbing experiments in 2018, using the same chemical mixture in 50\% daily static renewal experiments ( $n=2$ per analysis). Rows in Italic font indicate nominal concentrations of mixture compounds that could not be analytically quantified due to detection limitations. $\mathrm{LDL}=$ method detection limit; $\mathrm{nm}=$ ambient concentrations that were not measured; na $=$ not applicable.

\begin{tabular}{|c|c|c|c|c|c|c|c|c|c|}
\hline Chemical & Year & & Method & LDL & $\log K_{o w} 1$ & Ambient & Low & Medium & High \\
\hline \multirow{2}{*}{ metformin } & 2017 & \multirow{2}{*}{ anti-diabetic } & \multirow{2}{*}{ LC-MS } & \multirow{2}{*}{60} & \multirow{2}{*}{-2.64} & 85 & 34 & 1995 & 19,172 \\
\hline & 2018 & & & & & 667 & 885 & 2129 & 14,748 \\
\hline \multirow{2}{*}{ sulfamethoxazole } & 2017 & \multirow{2}{*}{ antibiotic } & \multirow{2}{*}{ LC-MS } & \multirow{2}{*}{60} & \multirow{2}{*}{0.89} & 6 & 121 & 253 & 4036 \\
\hline & 2018 & & & & & 445 & 83 & 885 & 5830 \\
\hline \multirow{2}{*}{ fexofenadine } & 2017 & \multirow{2}{*}{ antihistamine } & \multirow{2}{*}{ LC-MS } & \multirow{2}{*}{162} & \multirow{2}{*}{2.81} & 122 & 720 & 2173 & 18,173 \\
\hline & 2018 & & & & & 110 & 520.5 & 2236 & 18,638 \\
\hline desvenlafaxine & na & mood-altering & GC-MS & 360 & 2.72 & $\mathrm{~nm}$ & 218 & 583 & 5830 \\
\hline estrone & na & hormone & GC-MS & 4130 & 3.13 & $\mathrm{~nm}$ & 3 & 30 & 300 \\
\hline \multirow{2}{*}{ DEET } & 2017 & \multirow{3}{*}{$\begin{array}{l}\text { repellent } \\
\text { fragrance }\end{array}$} & \multirow{2}{*}{ LC-MS } & \multirow{2}{*}{55} & \multirow{2}{*}{2.02} & 609 & 1763 & 3654 & 16,463 \\
\hline & 2018 & & & & & 718 & 388 & 1838 & 12,859 \\
\hline $\mathrm{HHCB}^{1}$ & na & & GC-MS & 321 & 5.90 & $\mathrm{~nm}$ & 218 & 2180 & 21,800 \\
\hline \multirow{2}{*}{ benzotriazole } & 2017 & \multirow{2}{*}{ industrial } & \multirow{2}{*}{ GC-MS } & \multirow{2}{*}{75} & \multirow{2}{*}{1.44} & 288 & 2215 & 5408 & 68,075 \\
\hline & 2018 & & & & & 358 & 1350 & 8618 & 77,479 \\
\hline 4-Nonylphenol & $\begin{array}{l}2017 \\
2018\end{array}$ & surfactant & GC-MS & 17,800 & 5.76 & $\mathrm{~nm}$ & 400 & 4000 & 40,000 \\
\hline $\mathrm{TBEP}^{2}$ & $\begin{array}{l}2017 \\
2018\end{array}$ & plasticizer & GC-MS & 2260 & 3.75 & $\mathrm{~nm}$ & 1500 & 15,000 & 150,000 \\
\hline BPA & $\begin{array}{l}2017 \\
2018\end{array}$ & plasticizer & GC-MS & 2340 & 3.32 & $\mathrm{~nm}$ & 300 & 3000 & 30,000 \\
\hline & 2017 & herbicide & $\mathrm{I} C-\mathrm{MS}$ & & & 16 & 76 & 333 & 3103 \\
\hline atrazine & 2018 & herbicide & LC-MS & 65 & 2.61 & 45 & 93 & 394 & 2801 \\
\hline hromacil & 2017 & herbicide & $\mathrm{I} C-\mathrm{MS}$ & 150 & 211 & 6 & 61 & 156 & 1275 \\
\hline bromacil & 2018 & herbicide & $\mathrm{LC}-\mathrm{M} \mathrm{MS}$ & 150 & 2.11 & 10 & 28 & 171 & 1212 \\
\hline & 2017 & & & & & 5 & 35 & 161 & 1446 \\
\hline metolacnior & 2018 & nerbiciae & $\mathrm{LC}-\mathrm{M} \mathrm{MS}$ & 145 & 3.13 & 8 & 30 & 165 & 1316 \\
\hline
\end{tabular}

${ }^{1}$ all $\log \mathrm{K}_{\mathrm{ow}}$ from pubchem.ncbi.nlm.nih.gov, accessed on 1 December $2021{ }^{2}$ galaxolide. 


\section{Materials and Methods}

\subsection{Sample Collection}

On three occasions in 2018, we collected grab samples from five streams along the Hamakua Coast of Hawai'i (Table 1, Figure 1, Supplemental Table S2). Samples were chosen based on their accessibility as the steepness of the coastline only permits safe access to few streams. None of the streams contained any centralized wastewater infrastructure above the collection sites. All sampled streams (but not Waiakea Pond) also contained the target species S. stimpsoni. Two sampling events occurred during the wet season (19 March and 23 March 2018), and the third sample was taken during the summer (3 July 2018). Samples were collected from the main flow of each stream in disinfected, 1-L highdensity polyethylene bottles (Uline, Pleasant Prairie, WI, USA). Bottles were rinsed with methanol prior to sampling, and then rinsed three consecutive times with $\sim 150 \mathrm{~mL}$ of sample water prior to filling. Field blanks were prepared for each sampling event. Cleaned 1-L high-density polyethylene bottles (see above) were filled with deionized water (DI $\mathrm{H}_{2} \mathrm{O}$; generated by using a MilliporeSigma (Merck, Darmstadt, Germany) reverse-osmosis filtration system) on the morning of each sampling day. These bottles were taken to the field site, opened during the sampling, and returned with the field samples at the end of the day. All samples, including field blanks, were immediately chilled on wet ice and frozen within $3 \mathrm{~h}$ of collection. We also collected water samples from our 2017 and 2018 exposure treatments of $S$. stimpsoni (see below) in order to confirm concentrations of the compounds in our mixtures. Treatment water samples were collected using bottles prepared in the same manner as for grab samples and frozen immediately after collection. All frozen water samples were shipped to The College of Wooster (OH, USA; transfer time 48-72 h, samples arrived still frozen) for analysis as described below. Samples remained frozen until being thawed at $4{ }^{\circ} \mathrm{C}$ immediately prior to analysis.

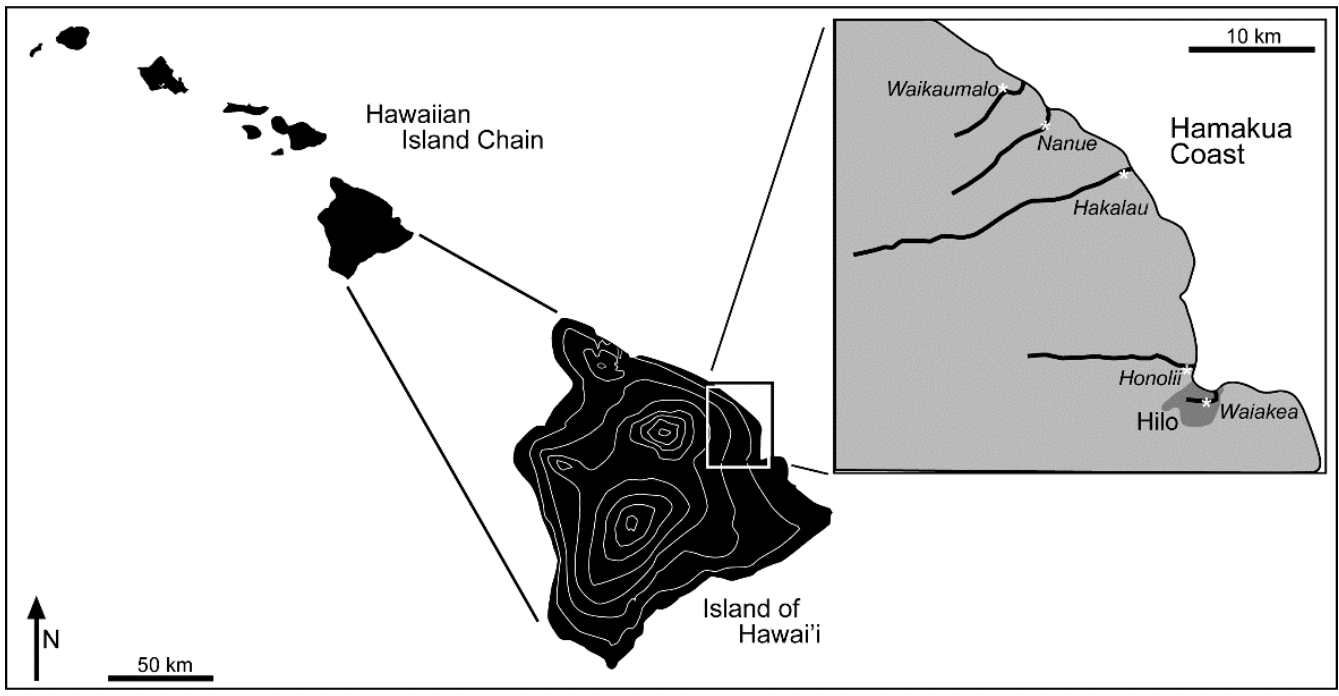

Figure 1. Sampling sites on the Island of Hawai'i (see Supplemental Table S2 for more information).

\subsection{Sample Extraction}

Samples were divided into 500-mL and 250-mL aliquots for analysis by liquid chromatography-mass spectrometry (LC-MS) or gas chromatography-mass spectrometry (GC-MS; Agilent, Santa Clara, CA, USA), respectively. Isotopically labeled surrogates (Tables S3 and S5) were added to the samples $(0.5 \mu \mathrm{g} / \mathrm{L}$ for LC-MS and $1.0 \mu \mathrm{g} / \mathrm{L}$ for GCMS). The procedure for analysis of CECs followed previously published protocols [20]. The $\mathrm{pH}$ was adjusted to 10.5 for LC-MS and to 3.5 for GC-MS, using $\mathrm{HCl}$ or $\mathrm{NaOH}$.

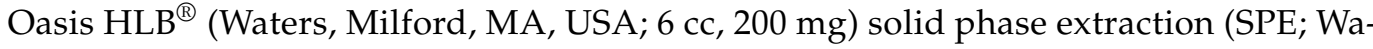
ters, Milford, MA, USA) cartridges were used for all extractions. For LC-MS sample extractions, SPE cartridges were conditioned with $5 \mathrm{~mL}$ of methanol followed by $5 \mathrm{~mL}$ 
of DI $\mathrm{H}_{2} \mathrm{O}$. After sample application at $<5 \mathrm{~mL} / \mathrm{min}$ followed by a $5 \mathrm{~mL}$ rinse with $\mathrm{H}_{2} \mathrm{O}$, cartridges were eluted with $5 \mathrm{~mL}$ of methanol, evaporated under $\mathrm{N}_{2}$, and reconstituted in $1.0 \mathrm{~mL}$ of $75: 25 \mathrm{H}_{2} \mathrm{O}$ : methanol with $1 \%(v / v)$ formic acid. The same procedure was used for GC-MS samples, except that SPE cartridges were eluted with $5 \mathrm{~mL}$ of acetone and reconstituted in $150 \mu \mathrm{L}$ of ethyl acetate.

\subsection{Analytical Methods}

LC-MS analytes (Table 1) were measured using Agilent 1200 Series HPLC (Santa Clara, CA, USA) coupled to an Agilent 6410 QqQ MS/MS, operated in positive ion mode using selective reaction monitoring. Analytes were separated on an Infinity Poroshell $120 \mathrm{C} 18 \mathrm{col}-$ umn $(2.7 \mu \mathrm{m}, 2.1 \times 100 \mathrm{~mm})$ at $60{ }^{\circ} \mathrm{C}$ with gradient elution, using $0.1 \%(v / v)$ formic acid in $\mathrm{H}_{2} \mathrm{O}$ and $0.1 \%(v / v)$ formic acid in methanol. The gradient profile, transition, and fragmentation parameters are provided in supplemental information Tables S1 and S2. Injection volume was $50 \mu \mathrm{L}$ and the flow rate was $0.5 \mathrm{~mL} / \mathrm{min}$. GC-MS analytes were measured using an Agilent 7890B/5977B GC-MS with an HP5-MS column $(30 \mathrm{~m} \times 250 \mu \mathrm{m} \times 0.25 \mu \mathrm{m})$ and $\mathrm{He}$ carrier gas. Detection was performed in selected ion monitoring mode. Instrument parameters and analyte ions are provided in supplemental information Tables S3 and S4. Representative LC-MS and GC-MS chromatograms are shown in supplemental information Figures S1 and S2. Calibration curves were measured for each analyte with added surrogate across concentrations ranging two to four orders of magnitude. All calibration curves were measured in tandem with samples. Field blanks and samples of tap water were run in conjunction with field samples.

\subsection{Fish Exposure Experiments}

Fish for each experiment were collected on the morning of the first exposure day (day 0) from the estuary of Hakalau Stream (Hamakua Coast, Island of Hawai'i, Figure 1). The transparent body of these fish indicated their recent arrival in fresh water [18] with limited exposure to CEC in freshwater streams. No current information exists to our knowledge about CEC presence in the adjacent marine environments. Fish were of similar size $(27.7+/-1.0 \mathrm{~mm})$. Sex could not be determined at this early stage of development [18] Fish were placed in coolers with aerated stream water and transported within two hours of capture to the Wailoa Fisheries Research Station of the Hawai'i Division of Aquatic Resources (DAR). Fish were randomly assigned to the four treatments (ambient stream water and low, medium, and high concentrations of the compound mixture) for a total of 15 fish per treatment. Mixture concentrations were chosen to accomplish a ten-fold difference in concentrations between low and medium, and a ten-fold difference between medium and high concentrations (Table 1). Water from an accessible natural stream (Honoli'i Stream) was used as the exposure medium, as migrating juvenile S. stimpsoni are sensitive to changes in the physicochemical characteristics of their ambient water, and do not respond well to reconstituted artificial laboratory waters (personal observation, HLS). Stream water was collected daily and augmented with a treatment-specific amount of chemical mixture using a 50\% daily static renewal experimental design. As the mixture chemicals were dissolved with the aid of an ethanol carrier, the control received a similar amount of ethanol. Three replicate experiments were conducted successively in 2017 to assess predator avoidance performance in exposed fish, and a fourth experiment was conducted in 2018 to examine climbing performance. All assays were conducted following $96 \mathrm{~h}$ of treatment exposure. Animal capture was permitted by the Division of Aquatic Resources, Department of Land and Natural Resources, State of Hawai'i. Animal use was approved and carried out under supervision of the St. Cloud State University Institutional Animal Care and Use Committee (protocol \#8-110).

\subsection{Predator Avoidance Assay}

We tested a total of 164 juvenile fish for predator avoidance performance at the end of their respective replicate exposures (2017) following established protocols [21,22]. Each 
fish was tested separately and only used once. Excluding 13 tests in which fish did not respond to the stimulus (and, therefore, did not generate a video recording), and 22 tests in which the recorded video could not be analyzed (i.e., fish swam out of field of view), we collected data from 129 escape trials across the three replicates. Predator avoidance trials were filmed in still stream water with a high-speed video camera (Fastec Highspec 2G, $1000 \mathrm{~Hz}$; Fastec, San Diego, CA, USA), using a mirror angled at $45^{\circ}$ to the clear bottom of rectangular, custom-built, Plexiglas tanks $(22.9 \times 10.2 \times 12.7 \mathrm{~cm})$ that allowed recordings of the ventral view of each fish [21]. For each trial, fish were given a minimum of $3 \mathrm{~min}$ to acclimate after being placed in the tank, allowing fish to settle on the bottom of the tank before stimulation. Fast-start escape responses were stimulated using a jet pulse of water aimed at the long axis of the animal, following our previously published methods [21,22]. To avoid experimental bias, we rotated fast-start tests across fish from different treatments and randomized replicates (e.g., control, low, medium, high, control, low ... ). For analysis, each fish was considered a unit of replication.

To calculate performance parameters, fifteen points along the midline of each fish, as well as the position of the stimulus at the commencement of each escape response, were digitized using DLT Data Viewer software [23]. The angle of attack was calculated from the first frame of each escape as the angle between two vectors: the first from the center of mass to the rostrum, and the second from the center of mass to the stimulus point [24]. Escape angles were measured as the angle between the initial position of the fish and the position of the fish at the end of stage one of the escape response (i.e., the point at which the head changes direction after initial reorientation during the fast start [25]). For each frame of a digitized sequence, a cubic spline interpolation function was used to identify the respective stretched-straight center of mass point along the length of the midline, from the tip of the snout. From this center of mass point, the smoothed position, velocity, and acceleration of the fish were calculated using a quintic spline [26]. We used cross-validation to find a global optimum smoothing parameter that could be used for all sequences [27]. All quintic splines were fit using the pspline package in $\mathrm{R}$ [28].

\subsection{Waterfall Climbing Assay}

We tested climbing ability and performance in 46 juvenile S. stimpsoni at the conclusion of the exposure experiment conducted in 2018. The exposure design was identical to that described above for experiments conducted in 2017. Excluding 10 non-climbers (no performance variables could be collected since the fish never entered the climbing surface and, therefore, the recording field of view), we calculated performance variables for 36 fish. Following methods published previously [11,29] climbing trials were conducted on an artificial waterfall at the DAR field station in Hilo, Hawai'i following each 96-h exposure. Fish were tested using a $1.5 \mathrm{~m}$ artificial waterfall, angled at $70^{\circ}$ from horizontal with stream water released down the chute to stimulate climbing $[14,30]$. To measure climbing performance, we filmed the dorsal view of each fish for the first $20 \mathrm{~cm}$ of the waterfall, using a Sony DTV 1020 digital camcorder (30Hz; Sony, Tokyo, Japan) [29]. Using iMovie software (Apple, Cupertino, CA, USA), individuals that climbed the full $20 \mathrm{~cm}$ were tracked frame by frame. From these recordings, we quantified climbing performance once per individual. These performance measurements included the percentage of time each fish spent in motion while climbing the $20 \mathrm{~cm}$ distance, climbing velocity during the climbing movements only $(\mathrm{cm} / \mathrm{s}$, excluding time spent at rest), and the total velocity $(\mathrm{cm} / \mathrm{s})$ reflecting the total time it took a fish to climb the $20 \mathrm{~cm}$ waterfall segment.

\subsection{Exposure-Activity Ratio (EAR)}

Given the paucity of existing data for the effects of contaminants on the biota of tropical islands, we used the ToxEval data base (https:/ / github.com/USGS-R/toxEval, accessed on 1 December 2021) to examine the biological activity that may be associated with the measured CEC concentrations in the current study. This analysis allows the derivatization of EARs, which calculate the ratio of a measured concentration, and a concentration that 
was reported to alter physiological or behavioral activity in a multitude of toxicological assays [31]. EAR values greater than one suggest a greater likelihood that the measured environmental concentration of a compound or mixture may invoke a biological response.

\subsection{Statistical Analysis}

Survival and predator avoidance stimulus response were analyzed using a Fisher's two-tailed exact test (Prism 6.1, San Diego, CA, USA). The effect of concentration treatment on peak acceleration was analyzed in $\mathrm{R}$ (v3.6.1) using a linear mixed effects model with experiment number as a random effect (lme4; [32]). After confirming that parametric assumptions were met, climbing performance variables were assessed using a one-way ANOVA with Holm-Sidak's multiple comparison test (Prism 6.1).

\section{Results}

\subsection{Chemical Analysis}

Reliable measurement of analyte concentrations was done using isotopic dilution. A surrogate was used for each analyte tested by LC-MS added prior to extraction. Analyte recoveries ranged from 3-50\% (supplemental information Table S6) with metformin having the lowest recovery ( $3 \%$ on average). Absolute recoveries varied with a relative standard deviation of approximately 50\%, demonstrating the importance of isotopic dilution to maintain data quality. Low recoveries of metformin have been reported previously due to its high polarity unless alternative methods such as ion pairing reagents are used [20]. Recovery of other analytes were generally $<90 \%$ due the optimization of the method to extract a diverse range of polarities.

Detection limits (Table 1) were determined from calibration curves (see supplemental information Table S7 for calibration curve statistics). All environmental water samples contained mixtures of the target analytes (Figure 2) with aqueous phase concentrations varying by stream and sampling event.

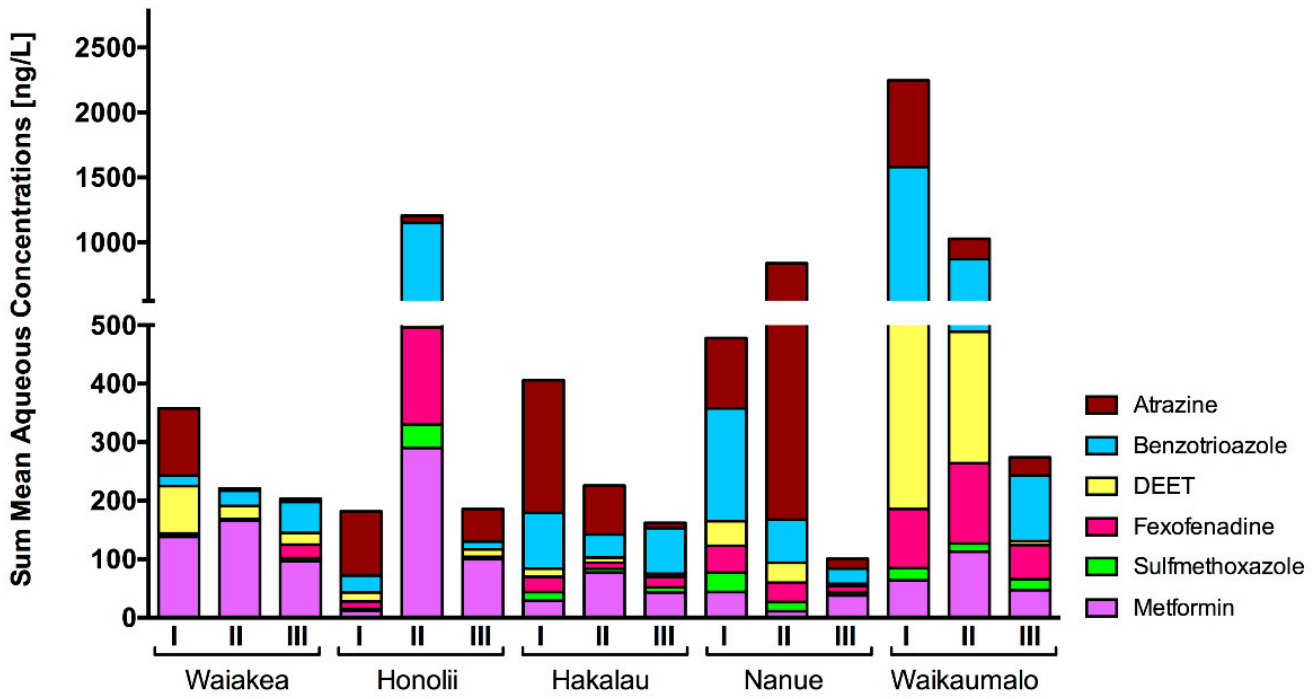

Figure 2. Contaminants of emerging concern (CEC) in Hawaiian streams. Sum of mean aqueous concentrations (duplicate analyses; ng/L) of eight CEC measured in five streams ( $x$-axis labels) along the Hamakua Coast of the Island of Hawai'i (from south to north) on three separate occasions (I = 19 March 2018; II = 23 March 2018; III = 3 July 2018). Compounds are stacked in same order as the legend (right side). Two compounds, bromacil and metolachlor, are excluded from the figure as their occurrence was limited to two samples each at low concentrations. The $y$ axis is separated into two segments at different scales to better illustrate compounds at lower concentrations.

Estimated concentrations are reported for five compounds analyzed by GC-MS based on QA/QC parameters (Table 1). The QA/QC limitations in measurement were either 
due to (i) the lack of a matched isotopically labeled surrogate with the same recovery, (ii) responses that were outside the linear range of the calibration curve, or (iii) detections in blanks. As we expected, our water sources (used for the reference and as dilution medium for the exposure treatments) contained trace amounts of CECs, highlighting the ubiquitous nature of these pollutants in anthropogenically impacted watersheds. Estimated CEC concentrations in spiked water used for predator avoidance fell within the expected range. Concentrations in the ambient reference (sum of concentrations: $1.3 \mu \mathrm{g} / \mathrm{L}$ ) had little discernable difference to those in the low exposure treatment $(2.9 \mu \mathrm{g} / \mathrm{L})$. However, medium and high treatments exhibited the expected ten-fold separation in concentrations $(17.6 \mu \mathrm{g} / \mathrm{L}$ and $163.4 \mu \mathrm{g} / \mathrm{L})$.

\subsection{Survival and Predator Avoidance Performance}

Survival was not significantly affected in any exposure experiment (Tables 2 and 3). The number of fish not responding to the predator stimulus did not differ between treatments in any experiment (two-sided Fisher's Exact Test, data not shown). Similarly, the time to respond to the stimulus (latency) was not altered by exposure (Table 2). Peak acceleration, a measure of the initial acceleration away from the predator stimulus, declined by approximately half in the high treatment of replicate 3 when compared to the ambient water treatment. However, the linear mixed model with replicate classified as a random effect did not identify significant differences between treatments for any of the dependent variables (latency, peak acceleration, peak velocity).

Table 2. Survival and predator avoidance performance in juvenile Sicyopterus stimpsoni exposed for $96 \mathrm{~h}$ to complex mixtures of CECs (2017). Discrepancies between survival and analyzed responses in these experiments reflect high-speed recordings in which fish swam out of the field of view, preventing analysis of trials. Superscript letters $\left({ }^{\mathbf{a}, \mathbf{b}}\right)$ in bold font rows indicate significant differences between $\left({ }^{a}\right)$ control, low, and medium treatments from $\left({ }^{b}\right)$ the high treatment $(p<0.05$, Kruskal-Wallis with Dunn's post-test).

\begin{tabular}{|c|c|c|c|c|c|}
\hline Replicate & Predation Experiment & Control & Low & Medium & High \\
\hline \multirow{6}{*}{1} & survival (\%) & 93.3 & 100 & 100 & 100 \\
\hline & no response & 1 & 2 & 0 & 1 \\
\hline & analyzed responses & 12 & 11 & 14 & 12 \\
\hline & latency (ms) & $20 \pm 7.3$ & $29 \pm 14$ & $22 \pm 9.6$ & $24 \pm 7.9$ \\
\hline & peak acceleration $\left(\mathrm{cm} / \mathrm{s}^{2}\right)$ & $3543 \pm 1077$ & $2664 \pm 1070$ & $2650 \pm 1136$ & $2779 \pm 1191$ \\
\hline & peak velocity $(\mathrm{cm} / \mathrm{s})$ & $95 \pm 18$ & $86 \pm 26$ & $80 \pm 23$ & $89 \pm 21$ \\
\hline \multirow{6}{*}{2} & survival (\%) & 93.3 & 93.3 & 93.3 & 100 \\
\hline & no response & 2 & 2 & 1 & 1 \\
\hline & analyzed responses & 9 & 11 & 12 & 14 \\
\hline & latency (ms) & $21 \pm 11$ & $24 \pm 16$ & $23 \pm 8.3$ & $21 \pm 9$ \\
\hline & peak acceleration $\left(\mathrm{cm} / \mathrm{s}^{2}\right)$ & $3134 \pm 1126$ & $2886 \pm 975$ & $3007 \pm 797$ & $3095 \pm 864$ \\
\hline & peak velocity $(\mathrm{cm} / \mathrm{s})$ & $98 \pm 18$ & $93 \pm 17$ & $99 \pm 14$ & $97 \pm 19$ \\
\hline \multirow{6}{*}{3} & survival (\%) & 93.3 & 80.0 & 86.7 & 60.0 \\
\hline & no response & 0 & 2 & 1 & 0 \\
\hline & analyzed responses & 13 & 7 & 10 & 4 \\
\hline & latency (ms) & $43 \pm 25$ & $38 \pm 19$ & $31 \pm 17$ & $22 \pm 11$ \\
\hline & peak acceleration $\left(\mathrm{cm} / \mathrm{s}^{2}\right)$ & $3057 \pm 659^{a}$ & $2914 \pm 651^{a}$ & $3047 \pm 902^{a}$ & $1374 \pm 780^{b}$ \\
\hline & peak velocity $(\mathrm{cm} / \mathrm{s})$ & $95 \pm 15$ & $95 \pm 11$ & $101 \pm 19$ & $79 \pm 29$ \\
\hline
\end{tabular}


Table 3. Survival and climbing success in juvenile Sicyopterus stimpsoni exposed for $96 \mathrm{~h}$ to complex mixtures of Contaminants of Emerging Concern (2018). Superscript letters $\left(^{\mathbf{a}, \mathbf{b}}\right)$ in bold font rows indicate significant differences between $\left({ }^{a}\right)$ low and $\left({ }^{b}\right)$ medium treatments $(p<0.05$, one-way ANOVA with Holm-Sidak's multiple comparison).

\begin{tabular}{ccccc}
\hline Climbing Experiment & Control & Low & Medium & High \\
\hline survival (\%) & 86.7 & 73.3 & 86.7 & 60.0 \\
non-climber & 3 & 2 & 3 & 2 \\
analyzed responses & 10 & 9 & 10 & 7 \\
time in motion (\%) & $62 \pm 14$ & $52 \pm 21$ & $56 \pm 20$ & $51 \pm 21$ \\
climb velocity (cm/s) $_{\text {total velocity (cm/s) }} \mathbf{0 . 3 8} \pm \mathbf{0 . 0 6}$ & $\mathbf{a b}$ & $\mathbf{0 . 4 7} \pm \mathbf{0 . 1 7 ^ { \mathbf { a } }}$ & $\mathbf{0 . 3 5} \pm \mathbf{0 . 0 6}$ & $\mathbf{0 . 4 1} \pm \mathbf{0 . 0 7}$ \\
ab \\
\hline
\end{tabular}

\subsection{Climbing Performance}

Neither survival nor the number of fish failing to climb the artificial waterfall were affected by exposure to any treatment in experiments 4 (two-sided Fisher's Exact Test; Table 3). Climbing velocity differed among treatments, driven by above performance among low treatment fish and below average performance among medium treatment fish $(p<0.05$ one-way ANOVA with Holm-Sidak's multiple comparison test; Table 3).

\section{Discussion}

\subsection{Presence of CEC in Hawaiian Streams}

The target CEC were found in most water samples irrespective of collection event or sampled stream (Figure 2). The presence and concentrations of these CEC in Hawaiian streams are congruent with findings from all settled continents [15,33-36]. The pattern of CEC occurrence and concentrations varied between sampling events and streams, likely reflecting the influence of nearby land-use and anthropogenic activities on stream pollution. For example, the anti-diabetic pharmaceutical metformin was the most prevalent CEC found in Waiakea Pond, exceeding $100 \mathrm{ng} / \mathrm{L}$ during all three sampling events. This pond and its watershed are located in the center of the town of Hilo, HI (Figure 1), the only larger population center among the sampled watersheds, where consumption of metformin is likely most prevalent among sampling locations. Concentrations of this drug in the range of 105-832 ng/L were reported for estuaries in Puget Sound (Washington, DC, USA; [37]) and above 10,000 $\mathrm{ng} / \mathrm{L}$ for three samples taken in the Laurentian Great Lakes tributaries [16]. A review of occurrence data for Europe determined a median measured environmental concentration of $235 \mathrm{ng} / \mathrm{L}$ [38]. Thus, the presence and concentrations of metformin in Hawaiian streams, especially in urban settings, are consistent with other studies.

In contrast to the urban setting of Waiakea Pond, streams sampled in rural areas of the Hamakua Coasts exhibited different chemical profiles for pharmaceuticals and personal care products. The antibiotic sulfamethoxazole was found in most samples, but usually at low ng/L concentrations. This is consistent with a study from Barbados [6] where this pharmaceutical was frequently detected below the level of quantitation. For two of three sampling events, the insect repellent DEET was present at concentrations approaching $500 \mathrm{ng} / \mathrm{L}$ at Waikaumalo Stream. A small park and swimming hole are located just upstream of the sampling site at Waikaumalo Stream, and mosquitos were anecdotally abundant during the first two sampling events during the spring rainy season. It is likely that park visitors and swimmers applied DEET to their skin prior to or during visits to this location. DEET is commonly detected in environmental water samples $[16,39]$ at concentrations similar to those observed in the current study. It is noteworthy that DEET has a short half-life of days to weeks, based on environmental conditions [40], suggesting that its presence in many water samples is related to recent compound use. The immediacy of a contaminant source for DEET is also affirmed by the lower concentrations of DEET during the summer sampling event when higher temperatures and lower rainfall suppress mosquito populations. The antihistamine fexofenadine was also prominent at Waikaumalo Stream at concentrations exceeding $100 \mathrm{ng} / \mathrm{L}$, which is consistent with other 
studies that have reported maximum environmental concentrations of over $1000 \mathrm{ng} / \mathrm{L}$ in North American streams [15,16]. However, its presence in Waikaumalo Stream and other sampled rivers cannot be readily explained by immediate application, as it is ingested in pill form and mostly excreted with feces [41]. Instead, it is more likely that nearby on-site residential septic or cesspool systems transmit this compound into aquifers and receiving streams $[39,42]$. Previous studies have documented poor removal rates for many pharmaceuticals in on-site septic systems when compared to municipal wastewater treatment plants [43]. On-site septic systems, cesspools or leaking sewer infrastructure are likely a pathway to streams for many pharmaceuticals and personal care products, which accounted for approximately half of the total measured CEC concentrations in streams along the Hamakua Coast.

Industrial compounds were also commonly detected, with aqueous benzotriazole concentrations at times exceeding $1 \mu \mathrm{g} / \mathrm{L}$. Benzotriazole (as part of a mixture of isomers referred to as tolyltriazole) is used in a great variety of applications including de-icing fluids (likely not a factor in Hawai'i), inert pharmaceutical ingredients, and most prominently as corrosion inhibitors. The coastal environment in Hawai'i requires frequent maintenance of steel bridges that span most stream valleys, and it is likely that corrosion inhibitors in paints and other metal applications contribute to the prevalence of this compound in Hawaiian streams. Benzotriazole is commonly detected in streams in industrialized countries [44]. In a multi-year, multi-stream study of Great Lakes tributaries, benzotriazole was detected in half of all water samples and at maximum concentrations exceeding $8 \mu \mathrm{g} / \mathrm{L}$ [16].

In the continental US, herbicides are among the most prevalent CEC detected in fresh waters. The same study of Great Lakes tributaries cited above [16] detected atrazine in 70\% of water samples and at concentrations of up to $814 \mathrm{ng} / \mathrm{L}$ (median $18.4 \mathrm{ng} / \mathrm{L}$ ). Similar to [16], atrazine was the most prevalent of the three analyzed herbicides in the current study, and its concentrations were highest during the earlier sampling events (I and II, Figure 1), which coincided with the agricultural application of this compound prior to the planting season (March 2018). Herbicides are also used by maintenance crews to reduce weed growth along the margins of the highway traversing all streams along the Hamakua Coast. In contrast to [16], the other two herbicides targeted in the current study were seldom detected (metolachlor was detected in $62 \%$ of samples by [16]). This difference may be the result of different supply or use patterns in Hawai' $i$ when compared to the Upper Midwest of the US.

\subsection{Biological Effects}

Exposure experiments conducted with native juvenile S. stimpsoni in March 2017 and March 2018 identified subtle effects in response to mixture exposures. Effects were limited to one replicate of the 2017 predator avoidance performance experiments (decline in peak acceleration), and one variable of the 2018 climbing performance experiment (changes in climbing velocity), with adverse effects found among fish from mixture treatments with higher concentrations (medium/high). These concentrations can be viewed as exceptional (medium) and worst-case (high) scenarios, and it is unlikely that fish are routinely exposed to concentrations of such strength on the Island of Hawai'i. However, the more populous and urbanized island of $\mathrm{O}^{\prime}$ ahu (seat of the state capital Honolulu) may be more likely to experience the higher exposure concentrations tested in the current study, based on prior assessments of pesticides and other organic contaminants in $\mathrm{O}^{\prime}$ ahu streams ([45] Brasher and Wolff, 2004). It is noteworthy that the endemic fauna of $\mathrm{O}^{\prime}$ ahu has been adversely affected by anthropogenic habitat degradation [46,47] with $S$. stimpsoni, the subject of the current study, rarely being observed in streams on this island [48-50].

The paucity of effects observed in the ambient and low mixture treatments (which were similar in total pollutant concentration) is consistent with the existing literature for other fish species. For example, a review of effects in fish exposed to metformin [51] reported few effects below $1 \mu \mathrm{g} / \mathrm{L}$. When effects were observed, these usually occurred in longer term exposures (weeks to months) and consisted of molecular or cellular changes, 
which were not assessed in the current study. An environmental risk assessment by [38] concluded that metformin did not pose a significant risk at environmental concentrations. Similarly, DEET is not considered harmful to fish at commonly observed environmental concentrations [40]. While few studies have evaluated the environmental risk of fexofenadine, ref. [52] reported little bioaccumulation potential for fexofenadine in sticklebacks (Gasterosteus acuelatus) and no behavioral alterations following exposure at $1.3 \mu \mathrm{g} / \mathrm{L}$. The corrosion inhibitor benzotriazole has been shown to bioaccumulate in fish tissue and may act as an endocrine disruptor, though the mechanism of its action remains to be resolved; however, based on a recent review by [44], it also appears to pose only minor ecological risk at environmental concentrations. Indeed, with the exception of HHCB and 4-nonylphenol, the compounds applied in the CEC mixture exposures have low $\mathrm{K}_{\mathrm{ow}}$ values, suggesting little bioaccumulation potential (Table 1). HHCB was found to bioaccumulate in fish species in a previous study [53]. However, the effect was highly species-specific, with the greatest bioaccumulation factors calculated for long-lived, bottom-dwelling eels. The compound 4-nonylphenol has been shown to bioconcentrate in algae, but did not bioaccumulate across the food chain to fishes [54]. Although the herbicide atrazine represents a ubiquitous contaminant in North American waters, its effects on exposed biota are controversial; ranging from the reported induction of behavioral changes and reduced sperm quality to no significant effects at similar, low $\mu \mathrm{g} / \mathrm{L}$ concentrations (reviewed by de [55]). Other compounds included in the complex mixtures were also not expected to cause adverse effects at low or medium concentrations in short-term exposure experiments.

\subsection{Mixtures and Exposure-Activity Ratios (EAR)}

CEC occurrence and concentrations as measured in the current study were used to derive EARs. Given the paucity of existing data for the effects contaminants on the biota of tropical islands and the subtle effects observed in our exposure experiments, we used the ToxEval data base (https:/ / github.com/USGS-R/toxEval, accessed on 1 December 2021) to provide some guidance to resource managers regarding the threat associated with CECs. This analysis allows the derivatization of EARs, which calculate the ratio of a measured concentration and a concentration that was reported to alter physiological or behavioral activity in a multitude of toxicological assays [31]. EAR values greater than one suggest that the measured environmental concentration of a compound or mixture is greater than the lowest concentration required to incur a biological response. Using the concentrations from the low treatment, ToxEval derived EARs for the CEC used in this study ranged from $10^{-3}-1$ for a series of biomarkers (Figure 3). Suggesting little likelihood of biological responses. The lack of effects is consistent with other recent findings. For example, ref. [56] reviewed 88 published mixture exposure studies, and found that multiple compounds in complex mixtures acted antagonistically in $41 \%$ of the experiments and were seldom $(16 \%)$ additive in their effect. In the current study, the compounds used likely act through many different modes of action and may not affect similar biological pathways. In the current study, estrone, bisphenol A, and 4-nonylphenol are all considered estrogenic, albeit at different potencies [57], which may account for the range of EARs observed for nuclear receptors and steroid hormone assays (Figure 3 ). In addition to the unlikely additivity of the complex mixture used in the current study, its short duration ( $96 \mathrm{~h}$ ) compared to other studies (often 21 days and longer) may reduce the likelihood of observing adverse effects. However, juvenile exposure during migration may have functional consequences later in life as a result of exposure-induced changes to performance and physiology. For example, bisphenol A, one of the compounds used in the current study, has been documented to stymy growth and alter stress performance in rainbow trout following in ovum exposure [58]. Lastly, many of the lowest observed effects concentrations (LOEC) for compounds in our mixture were derived by assessing molecular or cellular changes in exposed organisms that are phylogenetically distant to our study species. These changes may occur more quickly than alterations in innate or highly adaptive behaviors such as predator avoidance and waterfall climbing, respectively. Yet, extending the length of exposure would provide little 
environmental relevance for $S$. stimpsoni, as juveniles exit the estuarine environment as soon as they attain climbing ability (within $96 \mathrm{~h}$ of arrival in the estuary; [18]). In contrast, other species such as the economically and culturally important striped mullet (Mugil cephalus), reside in estuaries for much of their life cycle and might suffer greater exposure consequences as a result. Future studies could explore these biological parameters in greater detail.

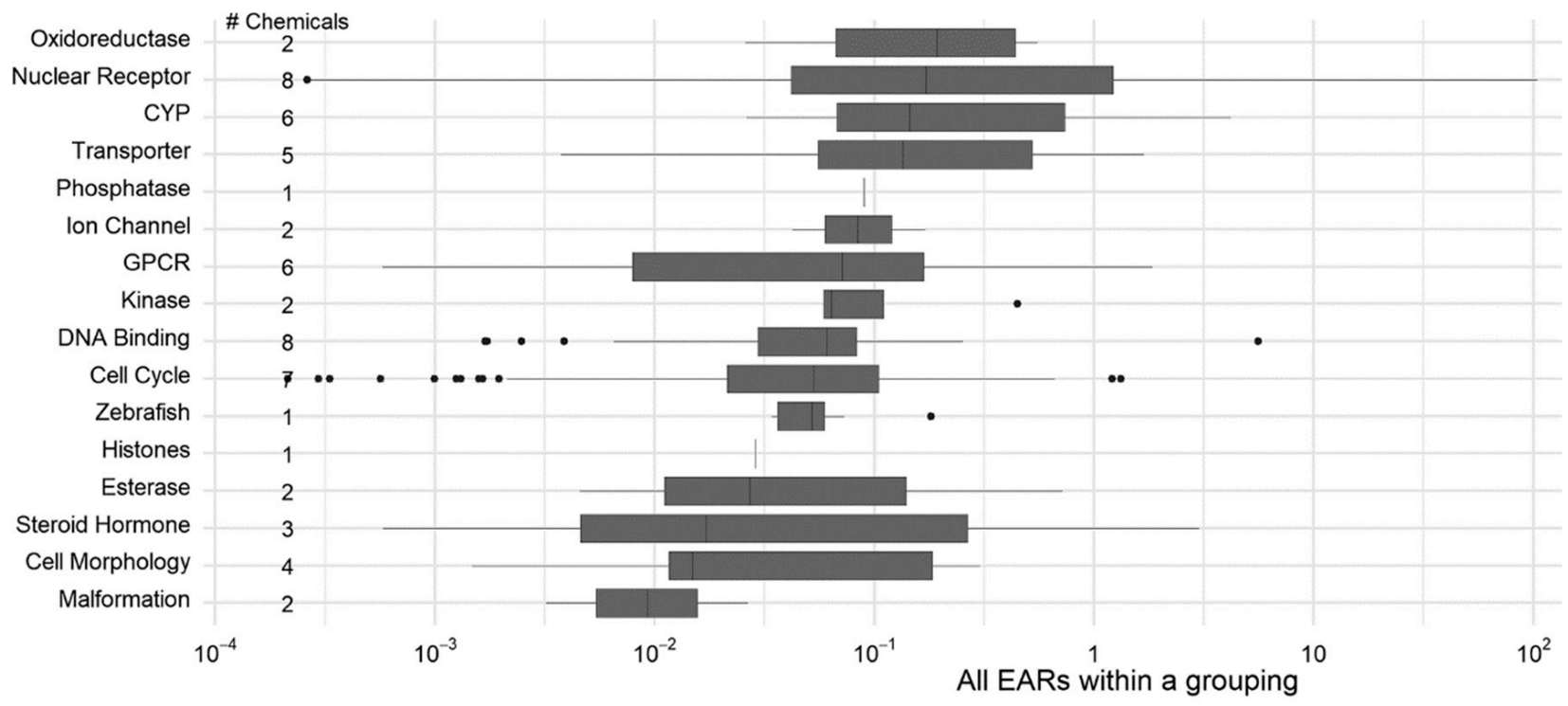

Figure 3. Exposure-activity ratios (EAR) for the CEC low treatment in the fish exposure studies. Each row summarizes high-throughput screening data from multiple assays along a similar biological pathway or organism. EARs reflect the sum of all compounds at their concentration in their lowest mixture treatment. Greater EARs suggest greater likelihood of biological responses to exposure. Box indicates 25-75 percentile with median. Whiskers indicate full data range (outliers are plotted separately).

\section{Conclusions}

Freshwater streams on the Island of Hawai'i contain mixtures of CEC similar in composition and concentrations to freshwaters in continental streams. Sources for these CEC are likely diverse and include direct water contact with personal care products, transport of CEC from on-site septic systems and leaking sewer infrastructure, and surface runoff from urban infrastructure and agricultural lands. Concentrations measured in the current study are unlikely to cause immediate harm to migrating juvenile stream fish based on the available toxicological literature and measurements of performance during multiple exposure experiments. However, the near ubiquitous presence of CEC in several rural streams should serve as a motivation to investigate CEC occurrence and potential effects in more heavily impacted Hawaiian streams and estuaries, where residence time and concentrations may be higher. Using native fish species and assays tailored around strong selective pressures for each species will render these investigations more meaningful than relying on standard assays for continental model species. The lack of available assays and information on molecular effects for species that are phylogenetically remote from standard toxicology model taxa complicates efforts to develop adequate risk assessment strategies for oceanic islands. In addition, developing more data for non-model species may improve confidence that existing data sets can be extrapolated to environmental settings not conforming with continental aquatic ecosystems. This study highlights the need to conduct ecotoxicological studies in a meaningful ecological context, especially when environments and species composition differ substantially from established model systems. Natural resource managers responsible for maintaining and restoring oceanic aquatic ecosystems are well advised to consider the specific conditions and challenges faced by their local aquatic fauna. 
Supplementary Materials: The following supporting information can be downloaded at: https: / / www.mdpi.com/article/10.3390/w14030275/s1, Figure S1: Representative HPLC-MS/MS chromatogram; Figure S2: Representative GC-MS chromatogram. Table S1: Solvent gradient for LCMS/MS. Mobile phase $[\mathrm{A}]=\mathrm{H}_{2} \mathrm{O}(0.1 \%$ formic acid $)$, Mobile phase $[\mathrm{B}]=$ Methanol $(0.1 \%$ formic acid); Table S2: Sampling sites; Table S3: MS parameters for dynamic multiple reaction monitoring ${ }^{1}$; Table S4: GC-MS temperature program; Table S5: GC-MS parameters for selected ion monitoring; Table S6: Analyte recoveries; Table S7: Calibration curve statistics.

Author Contributions: Conceptualization, K.M.D., T.S.S., P.L.E., R.W.B. and H.L.S.; methodology, K.M.D., P.L.E., T.C.S., R.W.B. and H.L.S.; formal analysis, K.M.D., C.J.G., N.J., P.L.E., J.A.F. and A.M.R.; writing-original draft preparation, K.M.D., T.S.S., R.W.B. and H.L.S.; writing-review and editing, all authors; project administration, H.L.S.; funding acquisition, K.M.D., C.J.G., P.L.E., J.A.F., R.W.B. and H.L.S. All authors have read and agreed to the published version of the manuscript.

Funding: This research was funded by Sigma Xi (K.M.D.), the American Society of Ichthyologists and Herpetologist (K.M.D.), the Society for Integrative and Comparative Biology (K.M.D.), Clemson Creative Inquiry grant \# 479 (R.W.B.), and a St. Cloud State University Short-Term Faculty Improvement Grant (\#211228; H.L.S.). The award of a Hellervik Prize to HLS assisted in the completion of this project. Support was provided by The College of Wooster Copeland Funding and Hamburger Collaborative Grant Program (C.J.G., J.A.F., P.L.E.).

Institutional Review Board Statement: The study was conducted in accordance with the Declaration of Helsinki, and approved by the Institutional Animal Care and Use Committee (IACUC) of St. Cloud State University (protocols \#8-103, approved 3 February 2017; and \#8-110, approved 2 February 2018).

Informed Consent Statement: Not applicable.

Data Availability Statement: All data are presented in the Supplemental Materials. Further information is available from the corresponding author (HLS) upon request.

Acknowledgments: We are grateful to Lance Nishiura, Troy Shimoda, Tim Shindo, and Naomi Ahu at the DAR Wailoa Fisheries Research Station in Hilo, Hawai'i for their patient support and hospitality. Thanks to Satomi Kohno for the EAR calculations.

Conflicts of Interest: The authors declare no conflict of interest.

\section{References}

1. DeMaagd, N. Water Demand in the Residential and Tourism Sectors: Evidence and Implications for Efficient Management. Ph.D. Thesis, University of Hawaii, Manoa, HI, USA, 2020; pp. 55-67. Available online: http://hdl.handle.net/10125/70364 (accessed on 1 December 2021).

2. Whittier, R.B.; El-Kadi, A.I. Human Health and Environmental Risk Ranking of On-Site Sewage Disposal Systsems for the Hawaiian Islands of Kauai, Molokai, Maui, and Hawaii; State of Hawaii Department of Health, Safe Drinking Water Branch: Waimalu, HI, USA, 2014.

3. Economy, L.M.; Wiegner, T.N.; Strauch, A.M.; Awaya, J.D.; Gerken, T. Rainfall and streamflow effects on estuarine Staphylococcus aureus and fecal indicator bacteria concentrations. J. Environ. Qual. 2019, 48, 1711-1721. [CrossRef]

4. Abaya, L.M.; Wiegner, T.N.; Beets, J.P.; Colbert, S.L.; Carlson, K.M.; Kramer, K.L. Spatial distribution of sewage pollution on a Hawaiian coral reef. Mar. Pollut. Bull. 2018, 130, 335-347. [CrossRef] [PubMed]

5. Yoshika, R.M.; Kim, C.J.S.; Tracy, A.M.; Most, R.; Harvell, C.D. Linking sewage pollution and water quality to spatial patterns of Porites lobata growth anomalies in Puako, Hawaii. Mar. Pollut. Bull. 2016, 104, 313-321. [CrossRef] [PubMed]

6. Edwards, Q.A.; Kulikov, S.M.; Graner-O'Neale, L.D.; Metcalf, C.D.; Sultana, T. Contaminants of emerging concern in surface waters in Barbados, West Indies. Environ. Monit. Assess. 2017, 189, 636. [CrossRef] [PubMed]

7. McDowall, R.M. Hawaiian biogeography and the islands' freshwater fish fauna. J. Biogeogr. 2003, 30, 703-710. [CrossRef]

8. Julius, M.L.; Blob, R.W.; Schoenfuss, H.L. The survival of Sicyopterus stimpsoni, an endemic amphidromous Hawaiian gobiid fish, relies on the hydrological cycles of streams: Evidence from changes in algal composition of diet through growth stages. Aquat. Ecol. 2005, 39, 473-484. [CrossRef]

9. Schoenfuss, H.L.; Blob, R.W. The Importance of Functional Morphology for Fishery Conservation and Management: Applications to Hawaiian Amphidromous Fishes; Bishop Museum Press: Honolulu, HI, USA, 2007; Volume 3, pp. 125-141.

10. Radtke, R.L.; Kinzie, R.A., III; Folsom, S.D. Age at recruitment of Hawaiian freshwater gobies. Environ. Biol. Fishes 1988, 23, 205-213. [CrossRef]

11. Schoenfuss, H.L.; Blob, R.W. Kinematics of waterfall climbing in Hawaiian freshwater fishes (Gobiidae): Vertical propulsion at the aquatic-terrestrial interface. J. Zool. 2003, 261, 191-205. [CrossRef]

12. Rearick, D.C.; Ward, J.; Venturelli, P.; Schoenfuss, H.L. Environmental oestrogens cause predation-induced population decline in a freshwater fish. R. Soc. Open Sci. 2018, 5, 181065. [CrossRef] [PubMed] 
13. All, L.N.R.; Monshi, M.; Siddiqua, Z.; Shields, J.; Alame, K.; Wahls, A.; Akemann, C.; Meyer, D.; Crofts, E.J.; Saad, F.; et al. Detection of endocrine disrupting chemicals in Danio rerio and Daphnia pulex: Step-one, behavioral screen. Chemosphere 2021, 271, 129442. [CrossRef]

14. Blob, R.W.; Kawano, S.M.; Moody, K.N.; Bridges, W.C.; Maie, T.; Ptacek, M.B.; Julius, M.L.; Schoenfuss, H.L. Morphological selection and the evaluation of potential tradeoffs between escape from predators and the climbing of waterfalls in the Hawaiian stream Goby Sicyopterus stimpsoni. Integr. Comp. Biol. 2010, 50, 1185-1199. [CrossRef] [PubMed]

15. Bradley, P.M.; Journey, C.A.; Romanok, K.M.; Barber, L.B.; Buxton, H.T.; Foreman, W.T.; Furlong, E.T.; Glassmeyer, S.T.; Hladik, M.L.; Iwanowicz, L.R.; et al. Expanded target-chemical analysis reveals extensive mixed-organic-contaminant exposure in U.S. streams. Environ. Sci. Technol. 2017, 51, 4792-4802. [CrossRef] [PubMed]

16. Elliott, S.M.; Brigham, M.E.; Kiesling, R.L.; Schoenfuss, H.L.; Jorgenson, Z.G. Environmentally Relevant Chemical Mixtures of Concern in U.S. Tributaries to the Great Lakes. Integr. Environ. Assess. Manag. 2018, 14, 509-518. [CrossRef]

17. Nilsen, E.; Smalling, K.L.; Ahrens, L.; Gros, M.; Miglioranza, K.S.B.; Pico, Y.; Schoenfuss, H.L. Critical Review: Grand challenges in assessing the adverse effects of contaminants of emerging concern on aquatic food webs. Environ. Toxicol. Chem. 2019, 38, 46-60. [CrossRef] [PubMed]

18. Schoenfuss, H.L.; Blanchard, T.A.; Kuamo'o, D.G.K. Metamorphosis in the cranium of postlarval Sicyopterus stimpsoni, an endemic Hawaiian stream goby. Micronesica 1997, 30, 93-104.

19. Keith, P. Biology and Ecology of Amphidromous Gobiidae of the Indo-Pacific and the Caribbean Regions. J. Fish Biol. 2003, 63, 831-847. [CrossRef]

20. Martin, J.; Buchberger, W.; Santos, J.L.; Alonso, E.; Aparicio, I. High-performance liquid chromatography quadrupole time-offlight mass spectrometry method for the analysis of antidiabetic drugs in aqueous environmental samples. J. Chromatogr. B 2012, 895, 94-101. [CrossRef] [PubMed]

21. Diamond, K.M.; Lagarde, R.; Schoenfuss, H.L.; Walker, J.A.; Ponton, D.; Blob, R.W. Relationship of escape performance with predator regime and ontogeny in fishes. J. Linnaean Soc. 2019, 127, 324-336. [CrossRef]

22. Diamond, K.M.; Schoenfuss, H.L.; Walker, J.A.; Blob, R.W. Flowing water affects fish fast-starts: Escape performance of the Hawaiian stream goby, Sicyopterus stimpsoni. J. Exp. Biol. 2016, 219, 3100-3105. [CrossRef]

23. Hedrick, T.L. Software techniques for two- and three-dimensional kinematic measurements of biological and biomimetic systems. Bioinspir. Biomim. 2008, 3, 034001. [CrossRef] [PubMed]

24. Domenici, P.; Blake, R.W. The kinematics and performance of fish fast-start swimming. J. Exp. Biol. 1997, 200, 1165-1178. [CrossRef]

25. Hale, M.E. Locomotor mechanics during early life history: Effects of size and ontogeny on fast-start performance of salmonid fishes. J. Exp. Biol. 1999, 202, 1465-1479. [CrossRef] [PubMed]

26. Walker, J.A.; Ghalambor, C.K.; Griset, O.L.; McKenney, D.; Reznick, D.N. Do faster starts increase the probability of evading predators? Funct. Ecol. 2005, 19, 808-815. [CrossRef]

27. Diamond, K.M.; Lagarde, R.; Griner, J.G.; Ponton, D.; Powder, K.E.; Schoenfuss, H.L.; Walker, J.S.; Blob, R.W. Interactions among multiple selective pressures on the form-function relationship in insular stream fishes. Biol. J. Linn. Soc. 2021, 134, 557-567. [CrossRef]

28. Ramsey, J.; Ripley, B. Pspline: Penalized Smoothing Splines. 2017. Available online: https://cran.r-project.org/web/packages/ pspline/pspline.pdf (accessed on 1 December 2021).

29. Blob, R.W.; Rai, R.; Julius, M.L.; Schoenfuss, H.L. Functional diversity in extreme environments: Effects of locomotor style and substrate texture on the waterfall-climbing performance of Hawaiian gobiid fishes. J. Zool. 2006, 268, 315-324. [CrossRef]

30. Blob, R.W.; Bridges, W.C.; Ptacek, M.B.; Maie, T.; Cediel, R.A.; Bertolas, M.M.; Julius, M.L.; Schoenfuss, H.L. Morphological selection in an extreme flow environment: Body shape and waterfall-climbing success in the Hawaiian stream fish Sicyopterus stimpsoni. Integr. Comp. Biol. 2008, 48, 734-749. [CrossRef] [PubMed]

31. Becker, R.A.; Friedman, K.P.; Simon, T.W.; Marty, M.S.; Patlewicz, G.; Rowlands, J.C. An exposure: Activity profiling method for interpreting high-throughput screening data for estrogenic activity-proof of concept. Regul. Toxiol. Pharmacol. 2015, 71, 398-408. [CrossRef] [PubMed]

32. Bates, D.; Mäechler, M.; Bloker, B.; Walker, S. Fitting linear mixed-effects models using lme4. J. Stat. Soft. 2015, 67, 1-48. [CrossRef]

33. Starling, M.C.V.M.; Amorim, C.C.; Leao, M.M.D. Occurrence, control and fate of contaminants of emerging concern in environmental compartments in Brazil. J. Hazard. Mater. 2019, 372, 17-36. [CrossRef] [PubMed]

34. Tiedeken, E.J.; Tahar, A.; McHugh, B.; Rowan, N.J. Monitoring, sources, receptors, and control measures for three European Union watch list substances of emerging concern in receiving waters-A 20 year systematic review. Sci. Total Environ. 2017, 574, 1140-1163. [CrossRef] [PubMed]

35. Odendaal, C.; Seaman, M.T.; Kemp, G.; Patterton, H.E.; Patterton, H.-G. An LC-MS/MS based survey of contaminants of emerging concern in drinking water in South Africa. S. Afr. J. Sci. 2015, 111, 1-6. [CrossRef]

36. Richardson, B.J.; Lam, P.K.S.; Martin, M. Emerging chemicals of concern: Pharmaceuticals and personal care products (PPCPs) in Asia, with particular reference to South China. Mar. Pollut. Bull. 2005, 50, 913-920. [CrossRef] [PubMed]

37. Meador, J.P.; Bettcher, L.F.; Ellenberger, M.C.; Senn, T.D. Metabolic profiling for juvenile Chinook salmon exposed to contaminants of emerging concern. Sci. Total Environ. 2020, 747, 141097. [CrossRef] 
38. Caldwell, D.J.; D’Aco, V.; Davidson, T.; Kappler, K.; Murray-Smith, R.J.; Owen, S.F.; Robinson, P.F.; Simon-Hettich, B.; Straub, J.O.; Tell, J. Environmental risk assessment of metformin and its transformation product guanylurea: II. occurrence in surface waters of Europe and the United States and derivation of predicated no-effects concentrations. Chemosphere 2019, 216, 855-865. [CrossRef] [PubMed]

39. Guyader, M.; Warren, L.; Green, E.; Proudian, A.; Kiesling, R.; Schoenfuss, H.L.; Higgins, C.P. Trace Organic Contaminant (TOrC) Mixtures in Minnesota Littoral Zones: Effects of On-Site Wastewater Treatment System (OWTS) Proximity and Biologic Impact. Sci. Total Environ. 2018, 626, 1157-1166. [CrossRef] [PubMed]

40. Weeks, J.; Guiney, P.; Nikiforov, A. Assessment of the environmental fate and ecotoxicity of N,N-diethyl-m-toluamide (DEET). Integr. Environ. Assess. Manag. 2012, 8, 120-134. [CrossRef]

41. U.S. Department of Health and Human Services. National Library of Medicine TOXNET; Toxicological Data Network; U.S. Department of Health and Human Services: Washington, DC, USA, 2017. Available online: https://toxnet.nlm.nih.gov/ newtoxnet/index.html (accessed on 21 December 2019).

42. Swartz, C.H.; Reddy, S.; Benotti, M.J.; Yin, H.; Barber, L.B.; Brownawell, B.J.; Rudel, R.A. Steroid estrogens, nonylphenol ethoxylate metabolites, and other wastewater contaminants in groundwater affected by a residential septic system on Cape Cod, MA. Environ. Sci. Technol. 2006, 40, 4894-4902. [CrossRef] [PubMed]

43. Du, B.; Price, A.E.; Scott, W.C.; Kristofco, L.A.; Ramirez, A.J.; Chambliss, C.K.; Yelderman, J.C.; Brooks, B.W. Comparison of contaminants of emerging concern removal, discharge, and water quality hazards among centralized and on-site wastewater treatment system effluents receiving common wastewater influent. Sci. Total Environ. 2014, 466, 976-984. [CrossRef] [PubMed]

44. Shi, Z.-Q.; Liu, Y.-S.; Xiong, Q.; Cai, W.-W.; Ying, G.-G. Occurrence, toxicity and transformation of six typical benzotriazoles in the envrionment: A review. Sci. Total Environ. 2019, 661, 407-421. [CrossRef] [PubMed]

45. Brasher, A.; Wolff, R.H. Relations between land use and organochlorine pesticides. PCBs, and semi-volatile organic compounds in streambed sediment and fish on the Island of Oahu, Hawaii. Arch. Environ. Contam. Toxicol. 2004, 46, 385-398. [CrossRef]

46. Brasher, A.M.D. Impacts of human disturbances on biotic communities in Hawaiian streams. BioScience 2003, 53, 1052-1060. [CrossRef]

47. Brasher, A.; Wolff, R.H.; Luton, C.D. Associations Among Land Use, Habitat Characteristics, and Invertebrate Community Structure in Nine Streams on the Island of Oahu, Hawaii, 1999-2001; U.S. Geological Survey: Sunrise Valley Drive, VA, USA, 2003.

48. Hathaway, C.B. Stream Channel Modification in Hawaii, Part C: Tolerance of Native Stream Species to Observed Levels of Environmental Variability. Colombia (MO): US Fish and Wildlife Service, National Stream Alteration Team; US Department of the Interior: Washington, DC, USA, 1978.

49. Moody, K.N.; Gagne, R.B.; Heim-Ballew, H.; Alda, F.; Hain, E.F.; Lisi, P.J.; Walter, R.P.; Higashi, G.R.; Hogan, J.D.; McIntyre, P.B.; et al. Invasion hotspots and ecological saturation of streams across the Hawaiian archipelago. Cybium 2017, 41, 127-156. [CrossRef]

50. Moody, K.N.; Wren, J.L.K.; Kobayashi, D.R.; Blum, M.J.; Ptacek, M.B.; Blob, R.W.; Toonen, R.J.; Schoenfuss, H.L.; Childress, M.J. Evidence of local adaptation in a waterfall-climbing Hawaiian goby derived from coupled biophysical modeling of larval dispersal and post-settlement selection. BMC Evol. Biol. 2019, 19, 88. [CrossRef]

51. Elizalde-Velázquez, G.A.; Gómez-Oliván, L.M. Occurrence, toxic effects and removal of metformin in the aquatic environments in the world: Recent trends and perspectives. Sci. Total Environ. 2020, 702, 134924. [CrossRef] [PubMed]

52. Sundlin, A. Ecotoxicological Effects on a Food-Web Exposed to Pharmaceuticals. Master's Thesis, UmeÅ University, Umeå, Sweden, 2015.

53. Gatermann, R.; Biselli, S.; Hühnerfuss, H.; Rimkus, G.G.; Hecker, M.; Karbe, L. Synthetic musks in the environment. Part 1: Species-dependent bioaccumulation of polycyclic ad. nitro musk fragrances in freshwater fish and mussels. Arch. Environ. Contam. Toxicol. 2002, 42, 437-446. [CrossRef] [PubMed]

54. Correa-Reyes, G.; Viana, M.T.; Matquez-Rocha, F.J.; Licea, A.F.; Ponce, E.; Vazques-Duhalt, R. Nonylphenol algal bioaccumulation and its effects through the trophic chain. Chemosphere 2007, 68, 662-670. [CrossRef] [PubMed]

55. de Albuquerque, F.P.; de Oliveira, J.L.; Moschini-Carlos, V.; Fraceto, L.F. An overview of the potential impacts of atrazine in aquatic environments: Perspectives for tailored solutions based on nanotechnology. Sci. Total Environ. 2020, 700, 134868. [CrossRef]

56. Jackson, M.C.; Loewen, C.J.G.; Vinebrooke, R.D.; Chimimba, C.T. Net effect of multiple stressors in freshwater ecosystems: A meta-analysis. Glob. Chang. Biol. 2016, 22, 180-189. [CrossRef] [PubMed]

57. Schultz, M.M.; Minarik, T.A.; Martinovic-Weigelt, D.; Curran, E.A.; Bartell, S.E.; Schoenfuss, H.L. Environmental estrogens in an urban aquatic ecosystem: II. Biological effects. Environ. Int. 2013, 61, 138-149. [CrossRef] [PubMed]

58. Aluru, N.; Leatherland, J.F.; Vijayan, M.M. Bisphenol A in oocytes leads to growth suppression and altered stress performance in juvenile rainbow trout. PLoS ONE 2010, 5, e10741. [CrossRef] 